\title{
An Eigenvalue Study of a Double Integrator Oscillator
}

\author{
Lindberg, Erik; Murali, K.; Tamasevicius, A.; von Wangenheim, Lutz
}

Published in:

Proceedings of the European Conference on Circuit Theory and Design

Link to article, DOI:

10.1109/ECCTD.2009.5274952

Publication date:

2009

Document Version

Publisher's PDF, also known as Version of record

Link back to DTU Orbit

Citation $(A P A)$ :

Lindberg, E., Murali, K., Tamasevicius, A., \& von Wangenheim, L. (2009). An Eigenvalue Study of a Double Integrator Oscillator. In Proceedings of the European Conference on Circuit Theory and Design: ECCTD'09 Divan Talya Hotel Convention Center Antalya Turkey, August 23 - August 27, 2009 (pp. 217-220). IEEE. https://doi.org/10.1109/ECCTD.2009.5274952

\section{General rights}

Copyright and moral rights for the publications made accessible in the public portal are retained by the authors and/or other copyright owners and it is a condition of accessing publications that users recognise and abide by the legal requirements associated with these rights.

- Users may download and print one copy of any publication from the public portal for the purpose of private study or research.

- You may not further distribute the material or use it for any profit-making activity or commercial gain

- You may freely distribute the URL identifying the publication in the public portal 


\title{
An Eigenvalue Study of a Double Integrator Oscillator
}

\author{
Erik Lindberg, IEEE Lifemember*, K. Murali ${ }^{\dagger}$, A. Tamasevicius ${ }^{\ddagger}$ and Lutz v.Wangenheim ${ }^{\S}$ \\ * DTU Elektro Department, 348 Technical University of Denmark, Lyngby, DK-2800, Denmark \\ e-mail: el@elektro.dtu.dk \\ $\dagger$ Department of Physics, Anna University, Chennai-600 025, India \\ e-mail:kmurali@ns.annauniv.edu \\ ‡ Semiconductor Physics Institute, A. Gostauto 11, Vilnius, LT-01108, Lithuania \\ e-mail: tamasev@pfi.lt \\ $\S$ Hochschule Bremen, University of Applied Sciences, Fb4, Neustadtswall 30, D-28199 Bremen, Germany \\ e-mail: wangenhm@etech.hs-bremen.de
}

\begin{abstract}
A tutorial study of an oscillator built from a loop of two active $R C$ integrators and an ideal inverter. As a reference the linear harmonic oscillator is modeled as a $L C$ circuit and as an ideal two integrator loop. The nonlinear amplifiers of the active $R C$ integrator circuits are assumed to be linear with time varying gain and the eigenvalues are found as function of time. A design strategy based on the time-constants of the integrators is presented.
\end{abstract}

\section{INTRODUCTION}

In the recent 20 years the classic circuit theory with analysis and synthesis of linear electrical circuits has more or less disappeared from the curriculum of the electrical and electronic engineering students. The digital systems dominate over the analog systems. But in the future possibly nonlinear analog systems will be used instead of or as a supplement to digital systems due to lower power consumption and higher speed [1]. The aim of this tutorial is to demonstrate that the classic circuit theory with poles and zeros (eigenvalues) may be used to gain insight in the behavior of nonlinear circuits.

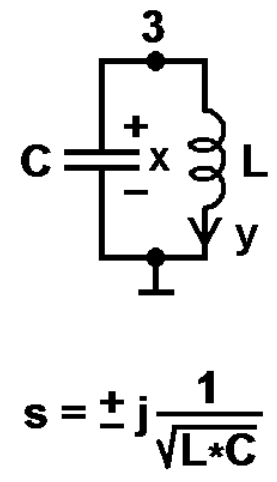

(a)

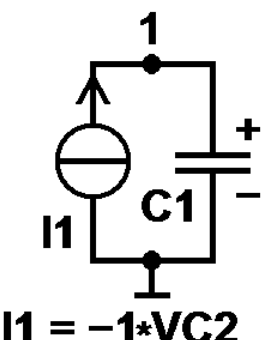

$$
s= \pm j \frac{1}{\sqrt{C 1 * C 2}}
$$

(b)

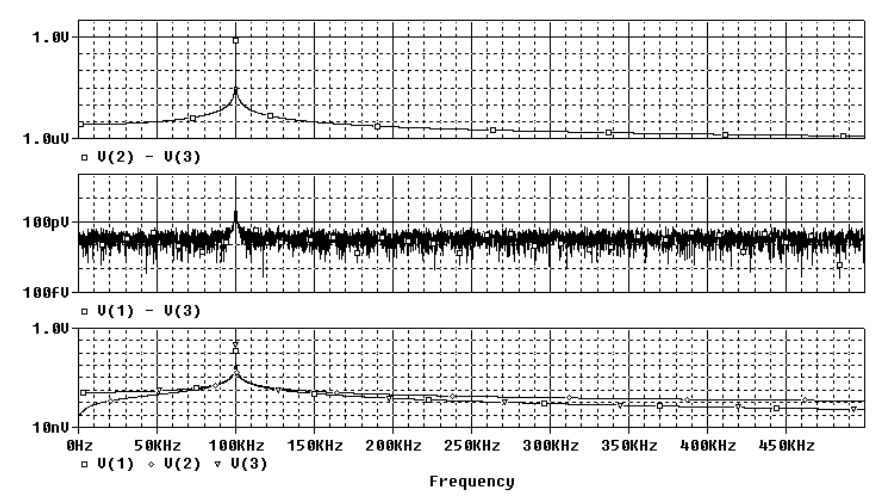

Fig. 2. Comparison of Harmonic Oscillator Models.

FFT analysis. $\quad \mathrm{V}(1)=\mathrm{V}(3)=\cos (\mathrm{t}), \quad \mathrm{V}(2)=\sin (\mathrm{t})$

\section{HARMONIC OSCILlATOR MODELS}

The harmonic oscillator may be modeled as a capacitor coupled in parallel to a coil, Fig. 1(a). If the initial condition is a voltage across the capacitor and a current equal to zero through the coil the voltage becomes a cosine of time and the current becomes a sine of time. The capacitor may be modeled as a current source controlled by the time derivative of its voltage. The coil may be modeled as a voltage source controlled by the time derivative of its current. As variables we choose the voltage across the capacitor: $x$, and the current through the coil: $y$, (state variables). We choose voltage $V$ and current $I$ as variables because they are easy to measure (signals). We should use charge $q=C * V$ and flux $\phi=L * I$ as variables because they represent the energy in the system. Unfortunately they are difficult to measure. In the real world charge and flux are nonlinear functions of voltage and current. Note that current is time derivative of charge $I=d q / d t$ and voltage is time derivative of flux $V=d \phi / d t$. Charge provide the coupling between the chemical world and the electrical world (electrolysis). Flux provide the coupling between the mechanical world and the electrical world (generators, motors). Capacitors and coils are memory elements. The resistor 
with memory - the memristor $\phi=M * q$ - has recently been implemented in the real world [2].

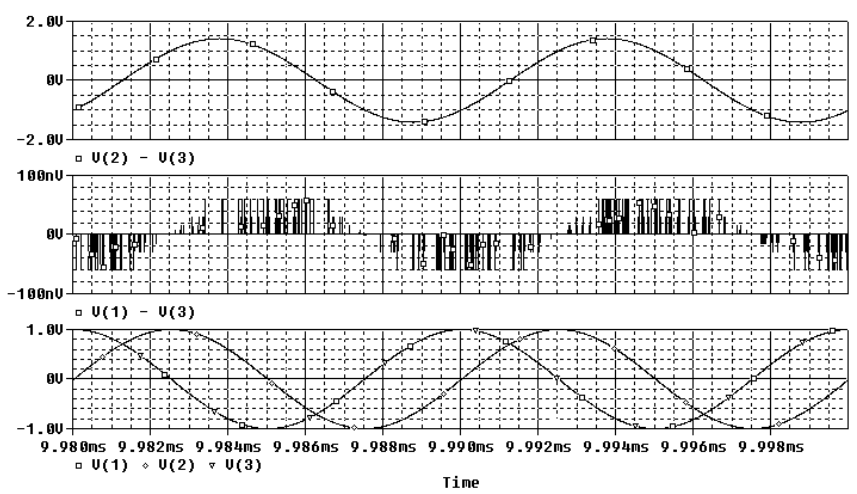

Fig. 3. Comparison of Harmonic Oscillator Models.

Time analysis. $\quad \mathrm{V}(1)=\mathrm{V}(3)=\cos (\mathrm{t}), \quad \mathrm{V}(2)=\sin (\mathrm{t})$

Now the harmonic oscillator may be modeled (defined) by means of two first order differential equations

$$
\begin{aligned}
& L \frac{d y}{d t}=+x \\
& C \frac{d x}{d t}=-y
\end{aligned}
$$

The two equations may be combined into a second order differential equation.

$$
\frac{d^{2} x}{d t^{2}}+\frac{x}{L C}=0
$$

The roots of the characteristic polynomial - the eigenvalues are a complex pole pair $s= \pm j * \omega$ on the imaginary axis where $\omega=2 \pi f$. With $\omega^{2}=1 /(L C)$ the frequency becomes $f=1 /[2 \pi \sqrt{(L C)}]$. The amplitude is given by the initial condition.

An ideal integrator may be modeled as a capacitor loaded current source. The voltage of the capacitor is the time integral of the current source. By means of two ideal integrators the harmonic oscillator may be modeled as shown in Fig. 1(b).

The figures Fig. 2 and Fig. 3 show a PSpice comparison of two $100 \mathrm{kHz}$ oscillators with the following component values: $L 3=1.591549431 \mu H, \quad C 3=1.591549431 \mu F \quad$ and $C 1=C 2=1.591549431 \mu F$. With an accuracy of $R E L T O L=1 \mu=1 e-6$ in PSpice a very close agreement between the models is observed.

Linear steady state oscillators are mathematical fiction. In the real world linear systems are always damped due to losses. Some kind of non-linearity must be introduced in order to obtain steady state oscillations. Oscillators are non-linear systems. It is to be expected that oscillators based on a double integrator will behave very close to sinusoidal so they have been reported frequently in the literature [3], [4], [5], [6], [7], [8], [9], [10], [11], [12]. In the following a double integrator oscillator based on operational amplifiers is investigated.

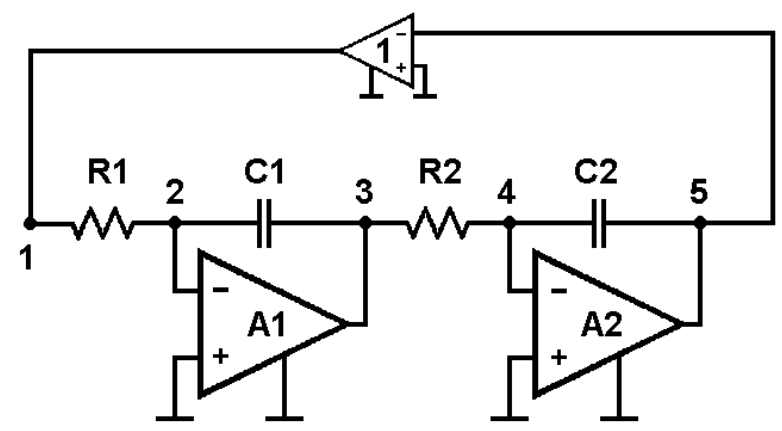

Fig. 4. Double integrator oscillator. $\quad V(1)=-V(5)$

\section{DOUble INTEGRATOR OSCILlatoR}

The circuit is a dedicated analogue computer circuit based on the definition of the sine and cosine functions: $d(\sin (t)) / d t=\cos (t)$ and $d(\cos (t)) / d t=-\sin (t)$. Input to the first integrator is $-\sin (t)$ which give rise to input $\cos (t)$ of the second integrator with output $\sin (t)$ to be inverted for feed-back to the first integrator (see Fig. 4). Assuming ideal operational amplifiers $\left(A_{1}=A_{2}=\infty\right)$ the relation between the components and the frequency becomes $\omega_{0}^{2}=\left(2 \pi f_{0}\right)^{2}=1 /\left(\tau_{1} * \tau_{2}\right)$ where $\tau_{1}=R_{1} * C_{1}$ and $\tau_{2}=R_{2} * C_{2}$ are the time constants of the integrators. If we choose $R_{1}=R_{2}=R=10 \mathrm{k} \Omega$ and $C_{1}=C_{2}=$ $C=15.91549431 \mathrm{nF}$ the nominal oscillating frequency becomes $f_{o}=1 \mathrm{kHz}, \tau_{1}=\tau_{2}=\tau=159.1549431 e-6$, $\omega_{o}=1 /(R C)=6.283185308 e+3=2 \pi f_{o}$.

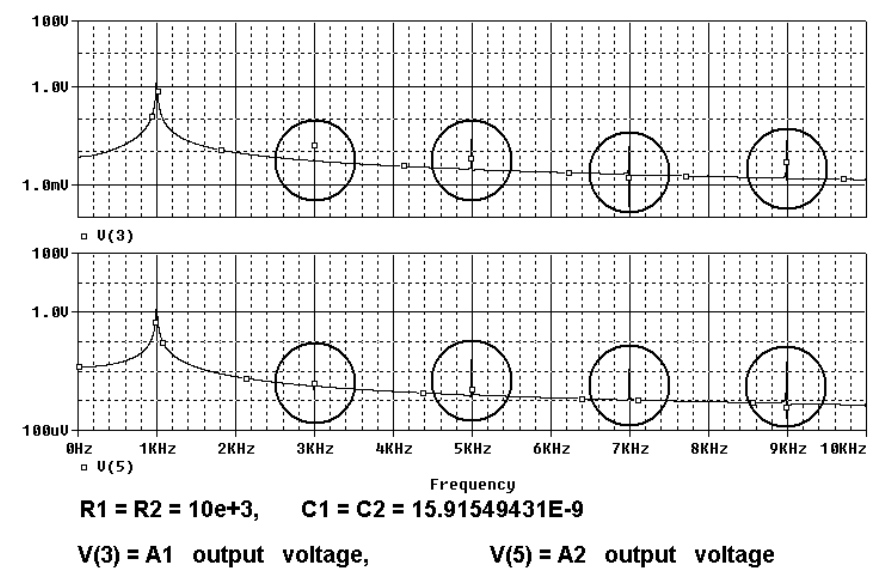

Fig. 5. Frequency spectrum. Logarithmic y-axis.

\section{A. PSpice analysis}

Now the two ideal operational amplifiers are replaced with PSpice op-amp macro-models, $\mu \mathrm{A} 741$ and an ideal PSpice inverter model (EVA3 11050 - 0 ) is introduced. The power supply is \pm 22 volts.

Figure 5 shows the frequency spectrum of the oscillator in steady state (FFT analysis over $800 \mathrm{~ms}$ ). Higher harmonics may be observed. In this case - where the resistors $R_{1}$ and $R_{2}$ are chosen equal and the capacitors $C_{1}$ and $C_{2}$ are chosen equal 


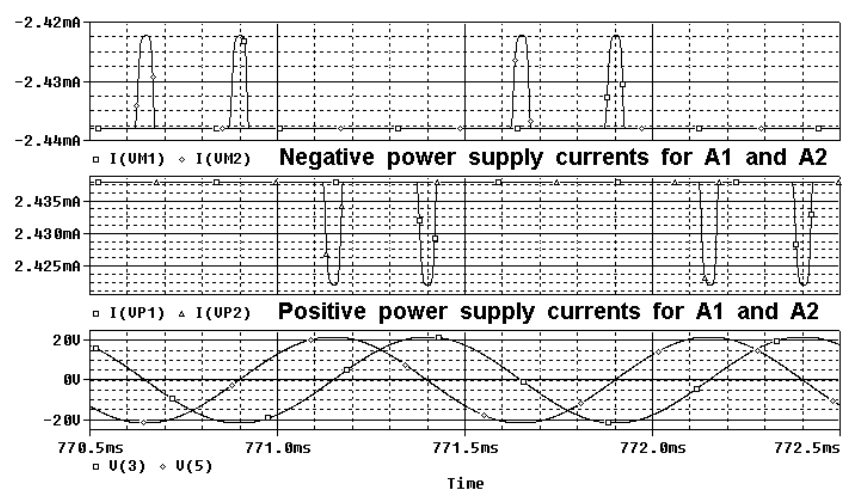

Fig. 6. Amplifier output voltages $V(3), V(5)$ and Power supply currents.

- clipping of both amplifier output voltages $V(3)$ and $V(5)$ is observed, Fig.6.

Figure 6 shows that energy is transferred to the amplifiers as very narrow pulses at the maximums of the output voltages. This behavior is very similar to the behavior of the pendulum clock where the escape mechanism [13] delivers the energy as pulses when the angel from vertical is zero and the weights go down a step changing potential energy into a kinetic energy impulse. For small swing - i.e. when $\mathrm{x}$ and $\sin (\mathrm{x})$ are almost equal - the pendulum clock is very close to a damped linear oscillator with very high quality factor and no harmonics. A strategy for design of electronic oscillators with minimum distortion could be optimization of the energy impulses observed.

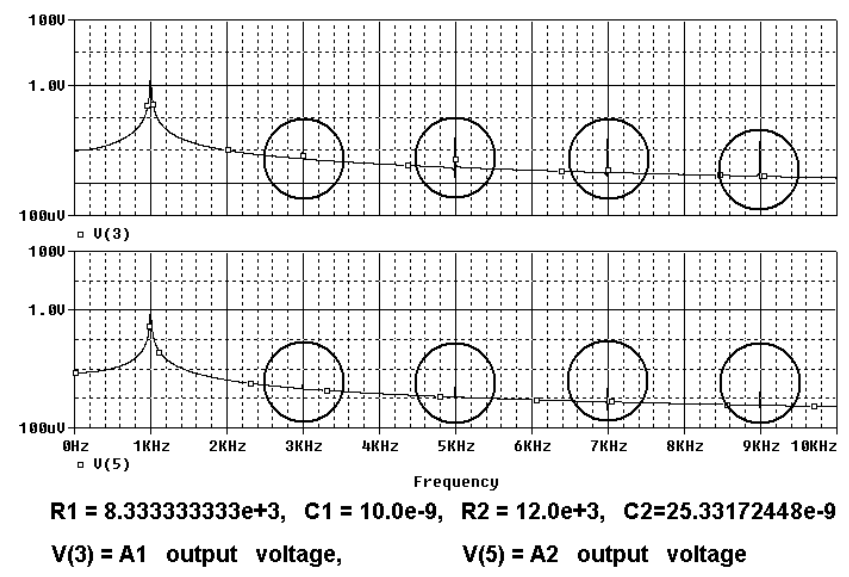

Fig. 7. Frequency spectrum. Logarithmic y-axis.

A large number of PSpice simulations have been made with various combinations of the values of the two resistors and the two capacitors. Apparently it is possible to remove the energy impulses in connection with one of the amplifiers so that the harmonics in the output voltage becomes smaller. The following PSpice results demonstrates this assertion and gives more insight in the behavior of the oscillator.

By means of the following values a number of PSpice simulations have been made: $R_{1}=8.333333333 \mathrm{k} \Omega, C_{1}=10.0 \mathrm{nF}$,

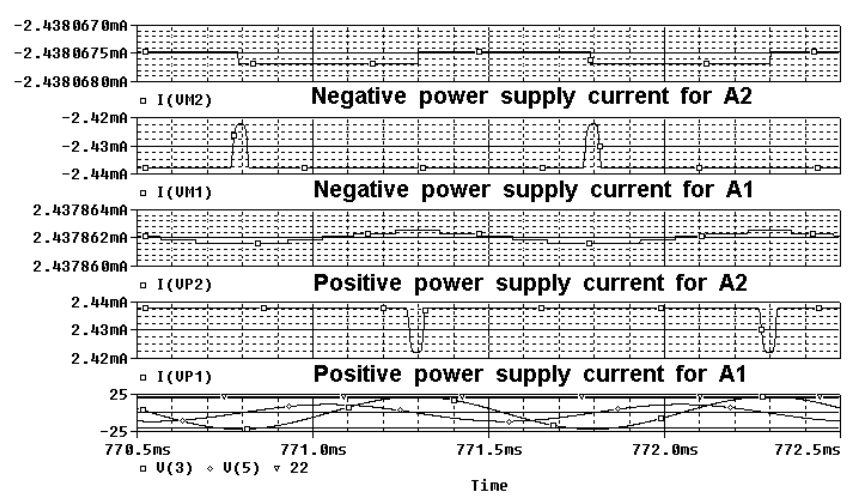

Fig. 8. Amplifier output voltages $V(3), V(5)$ and Power supply currents.

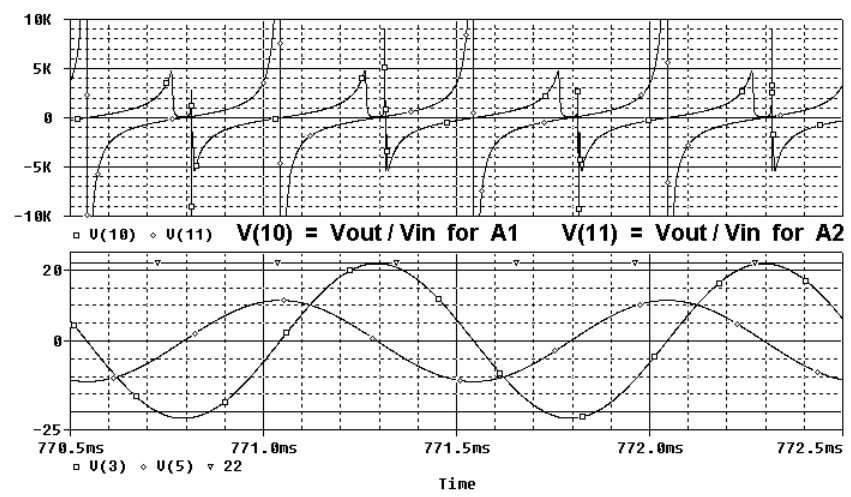

Fig. 9. Amplifier voltage gains and output voltages. $\mathrm{V}(3)=\mathrm{A} 1$ output voltage, $\mathrm{V}(5)=\mathrm{A} 2$ output voltage

$R_{2}=12.0 \mathrm{k} \Omega, C_{2}=25.33172448 \mathrm{nF}$, time constant amplifier $A_{1}: \tau_{1}=R_{1} * C_{1}=83.33333333 e-6$, time constant amplifier $A_{2}: \tau_{2}=R_{2} * C_{2}=303.9806938 e-6, \omega^{2}=1 /\left(\tau_{1} * \tau_{2}\right)=$ $39.47619124 e 6=(2 \pi f), f=0.9999718022 \mathrm{kHZ}$.

A comparison of Fig. 7 with Fig. 5 shows that the harmonics of the output voltage $V(5)$ of amplifier $A 2$ have been reduced. Figure 8 shows that the power is supplied to amplifier $A_{1}$ with an almost constant current of $2.44 \mathrm{~mA}$ and pulses of $15 \mu \mathrm{A}$ in the short clipping time intervals. The power is supplied to amplifier $A_{2}$ with an almost constant current of $2.438 \mathrm{~mA}$. A comparison of Fig. 8 with Fig. 6 shows that the pulses in the power supply currents of amplifier $A 2$ have disappeared. This result depends of course on the op-amp macro-model used. Experiments with $L M 741$ instead of $u A 741$ did not show pulses but reduction of harmonics was obtained. Figure 9 shows the amplifier gains as functions of time over two periods. It is seen that the gain is varying slowly in the interval \pm 5000 in the whole period except at the maximums of the amplifier output voltages where it vary between very large and very small values in very short time intervals.

\section{B. Eigenvalue calculation}

A study of the eigenvalues of the time-varying Jacobian of the linearized differential equations may give some insight in the behavior of the oscillator [14]. The linear time-varying approach (LTV) is a method to to calculate the time-varying 
eigenvalues (dynamic eigenvalues) of a nonlinear circuit [15], [16], [17], [18], [19]. To calculate the dynamic eigenvalues, the Riccati equation must be solved. In the following it is assumed that a nonlinear circuit can be treated as a time-varying linear circuit.

If it is assumed that the amplifiers are perfect - i.e. the input impedance is infinite and the output voltage is equal to the input voltage times a time varying constant $A$ i.e. $V_{\text {out }}=$ $\left(V_{+}-V_{-}\right) * A($ time $)$ - the characteristic polynomial of the circuit becomes

$$
s^{2}+2 \alpha s+\omega^{2}=0
$$

where

$$
2 \alpha=\frac{C_{1} R_{1}\left(1+A_{1}\right)+C_{2} R_{2}\left(1+A_{2}\right)}{C_{1} R_{1} C_{2} R_{2}\left(1+A_{1}\right)\left(1+A_{2}\right)}
$$

and

$$
\omega^{2}=\frac{1+A_{1} A_{2}}{C_{1} R_{1} C_{2} R_{2}\left(1+A_{1}\right)\left(1+A_{2}\right)}
$$

The roots are

$$
p_{1,2}=-\alpha \pm j \sqrt{\left(\omega^{2}-\alpha^{2}\right)}
$$

The roots of the characteristic polynomial (the poles) are found as function of time by means of a table of the gains as function of time found by means of PSpice. The result is shown in Fig. 10. It is seen that the imaginary part is close

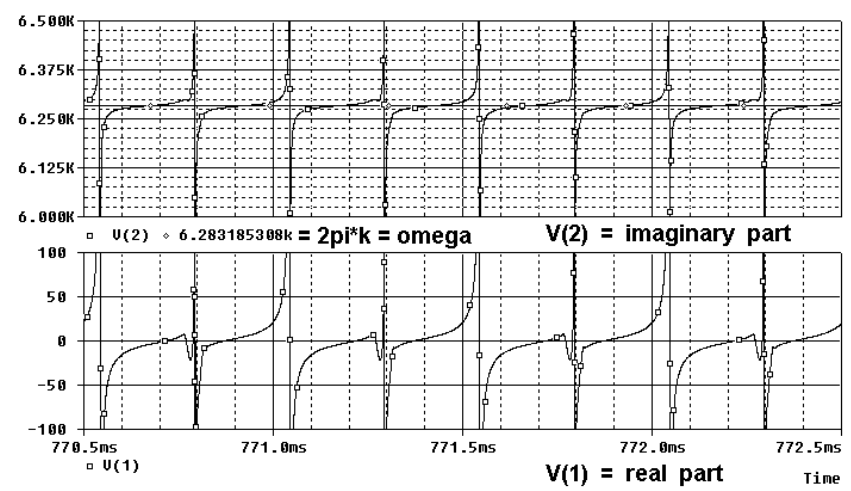

Fig. 10. Complex pole pair as function of time. $\omega_{0}=2 \pi^{*} 1 \mathrm{k}$.

to $\left.\omega_{o}=1 / \sqrt{(} R_{1} C_{1} R_{2} C_{2}\right)=6.283185308 e+3=2 \pi f_{o}$ and the real part is close to zero most of the time. Only in the short intervals - where the energy pulses come from the power supply - the complex pole pair goes to the real axis in the right half plane and split-up into two real roots which via zero and infinity comes back and unite into a complex pole pair as expected. The result is in agreement with the very little phase noise observed.

\section{CONCLUSION}

It is demonstrated that the classic circuit theory with poles and zeros (eigenvalues) may be used in connection with the design of a double integrator oscillator. The non-linear circuit is treated as a linear time-varying circuit. The parameters are chosen in such a way that the imaginary part of the poles of the linear time-varying circuit is as close as possible to $\omega_{0}$ over a period. The time constants of the integrators are chosen different in order to obtain minimum distortion of the output voltage of one of the amplifiers. The circuit is used mainly for low-frequency oscillators. The structure may be a candidate for IC implementation because it is based on resistors and capacitors only.

\section{REFERENCES}

[1] Henry Leung, "Analog Wideband Communications based on Nonlinear Dynamics",

http://www.mitacs.ca/main.php?mid=10000018\&pid=78\&proid=24

[2] R. Colin Johnson,"Will memristors prove irresistible ?", EE Times europe, September 8-21, pp.12-13, 2008.

[3] A. Foord, "Two-phase low-frequency oscillator", Electronic Engineering, Vol.46, Issue.562, pp.19-21, 1974.

[4] Frank Doorenbosch, "An Integrated Wide-Tunable Sine Oscillator", IEEE J. Solid-State Circuits, pp.401-403, June 1976.

[5] B. B. Bhattacharyya and S. Natarajan, "A new continuously tunable sinusoidal oscillator without external capacitors", Proc. IEEE, Vol.65, pp.1726-1727, Dec. 1977.

[6] S. Venkateswaran and Y. Venkataramani, "Comments on A New Continuously Tunable Sinusoidal Oscillator Without External Capacitors”, Proc. IEEE, Vol.67, No.10, pp.1452-1455, October 1979.

[7] B.J. Hosticka, W. Brockherde, U. Kleme and G. Zimmer, "Switchedcapacitor FSK modulator and demodulator in CMOS technology", IEEE J. Solid-State Circuits, Vol.SC-19, pp. 389-396, June 1984.

[8] J. Mulder, W.A. Serdijn, A.C. van der Woerd and A.H.M. van Roermund, "Design of current-mode companding J-domain dynamic circuits", pp.8/1-8/5, 1996 The Institution of Electrical Engineers. 8/1 Printed and published by the IEE, Savoy Place, London WC2R OBL, 1996.

[9] E. Vidal, A. Poveda and E. Arcon, "Amplitude stabilization in a triangular wave quadrature oscillator", 0-7803-3636-4197, IEEE 1083, pp.10831086, 1997.

[10] E. Vidal, A. Poveda and E. Alarcon, "Amplitude Control in a Triangular Wave Quadrature Oscillator", IEEE, pp.348-351, 1998.

[11] A.M. Soliman, "Synthesis of grounded capacitor and grounded resistor oscillators", Journal of the Franklin Institute, Vol.336, pp.735-746, 1999.

[12] L.B. Oliveira, J.R. Fernandes, L. M Filanovsky and C. J. M Verhoeven, "Wideband Two-Integrator Oscillator-Mixer", IEEE, pp.385-388, 2005.

[13] E. Lindberg, "Oscillators - an approach for a better understanding", Invited tutorial, Proc. of the European Conference on Circuit Theory and Design 2003, ECCTD'03, Cracow, Poland, 1-4 September 2003. http://server.elektro.dtu.dk/www/el/lindberg/el/public_html/elecctd03.pdf

[14] E. Lindberg, "Is the Quadrature Oscillator a Multivibrator ?", IEEE Circuits \& Devices Magazine, November/December 2004, Vol.20, No.6, pp.23-28, 2004.

[15] F.C.M. Kuijstermans, F.C.M., A. van Staveren, P. van der Kloet, F.L. Neerhoff, C.J.M. Verhoeven, "Dynamic behaviour of nonlinear circuits: the linear time-varying approach", NDES'98. Proceedings of the 6th International Specialist Workshop on Nonlinear Dynamics of Electronic Systems, Tech. Univ. Budapest, pp.279-285, 1998.

[16] F.L. Neerhoff, P. van der Kloet, A. van Staveren, C.J.M. Verhoeven, "Nonlinear electronics: a linear time-varying circuit approach", Proceedings IEEE 10th Annual Workshop on "Circuits, Systems and Signal Processing', pp.317-322, 1999.

[17] P. van der Kloet and F. L. Neerhoff, "Diagonalization algorithms for linear time-varying dynamic systems", Int. J. Syst. Sci., Vol.31, No.8, pp.10531057, 2000.

[18] P. van der Kloet and F.L. Neerhoff, "Modal factorization of time-varying models for nonlinear circuits by the Ricatti transform", ISCAS 2001. The 2001 IEEE International Symposium on Circuits and Systems, Vol.3, pp.553-556, 2001.

[19] F.M. Diepstraten, F.C.M. Kuijstermans, W.A. Serdijn, P. van der Kloet, A. van Staveren, F.L. Neerhoff, C.J.M. Verhoeven, and A.H.M. van Roermund, "Dynamic Behavior of Dynamic Translinear Circuits: The Linear Time-Varying Approximation", IEEE Trans. on Circuits and SystemsI: Fundamental Theory and Applications, Vol.48, No.11, pp.1333-1337, November 2001. 


\section{An Eigenvalue \\ Study of a \\ Double Integrator Oscillator}
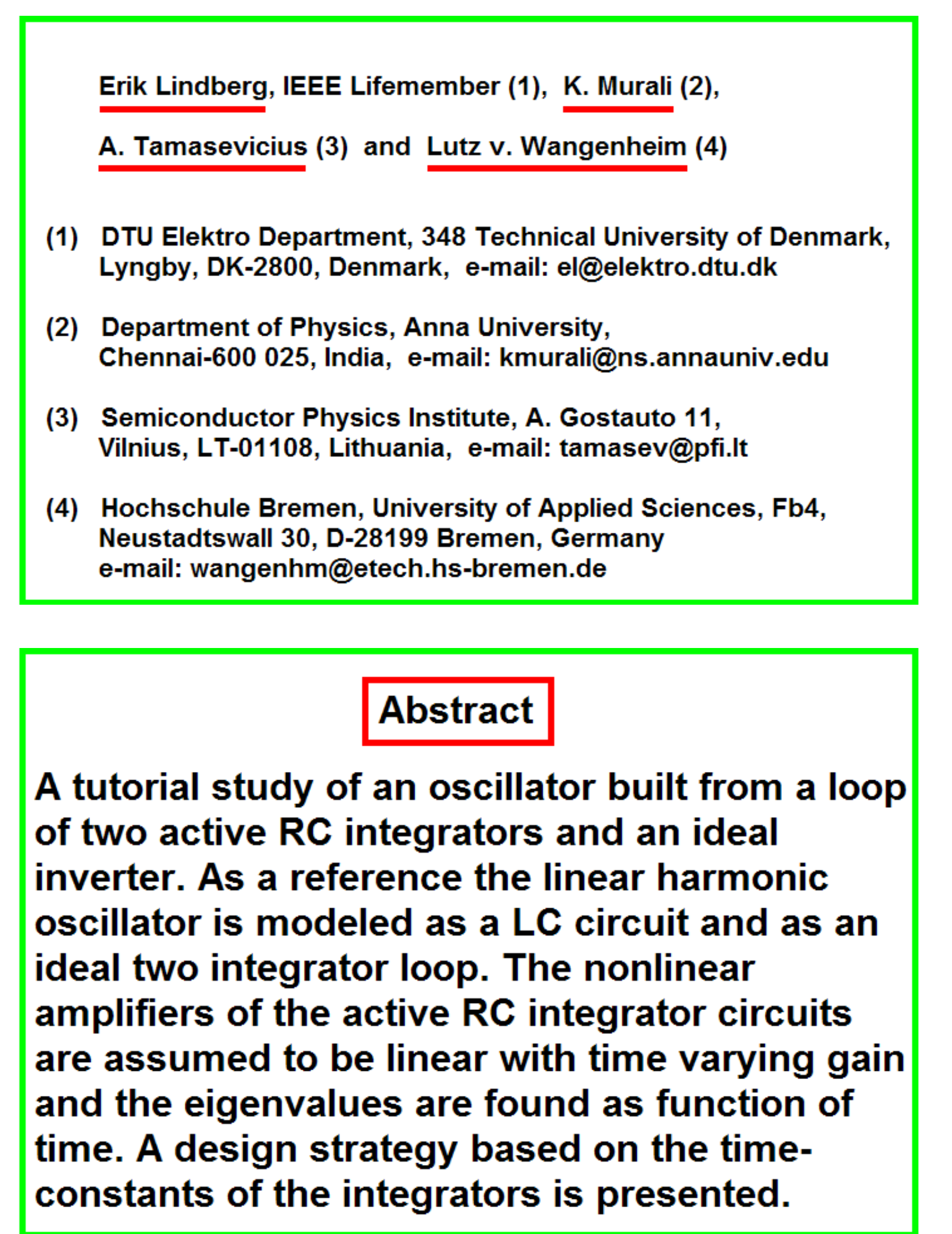

\begin{tabular}{|l|} 
The aim of this tutorial is to demonstrate \\
that the classic circuit theory with \\
poles and zeros (eigenvalues) \\
may be used to gain insight in \\
the behavior of nonlinear circuits
\end{tabular}

COMPUTER AIDED CIRCUIT ANALYSIS

- The kernel of analyzing nonlinear circuits
is the solution of a linear circuit

- All elements may be modelled

- During the iterations the elements
may be approximated with either
a dynamic value or a static value

dynamic value or a static value

- The CAPACITOR is a voltage controlled
current source (VCCS) controlled by the time derivative of its voltage:

$$
\mathrm{IC}=\mathrm{sC} * \mathrm{VC}=\mathrm{C} \frac{\mathrm{dVC}}{\mathrm{dt}}
$$

- The INDUCTOR is a current controlled
voltage source (CCVS) controlled by the time derivative of its current $\mathrm{VL}=\mathrm{sL}+\mathrm{L}=\mathrm{L} \frac{\mathrm{dIL}}{\mathrm{dt}}$

EXTENDED NODE EQUATIONS

- First order differential equations

- Variables: Node Potentials and
Impedance Branch Currents

- Current sources are
Admittance Branches

- Voltage sources are
Impedance Branches
By means of MEASUREMENTS you may
investigate the behaviour of the REAL WORLD By means of SIIMULATION you may investigate
the behaviour of your MODEL If you observe AGREEMENT betwe measurements and simulation
YOU BELEEVE IN YOUR MODEL

By means of a POSTER you may present
the slides of a LECTURE of several hours
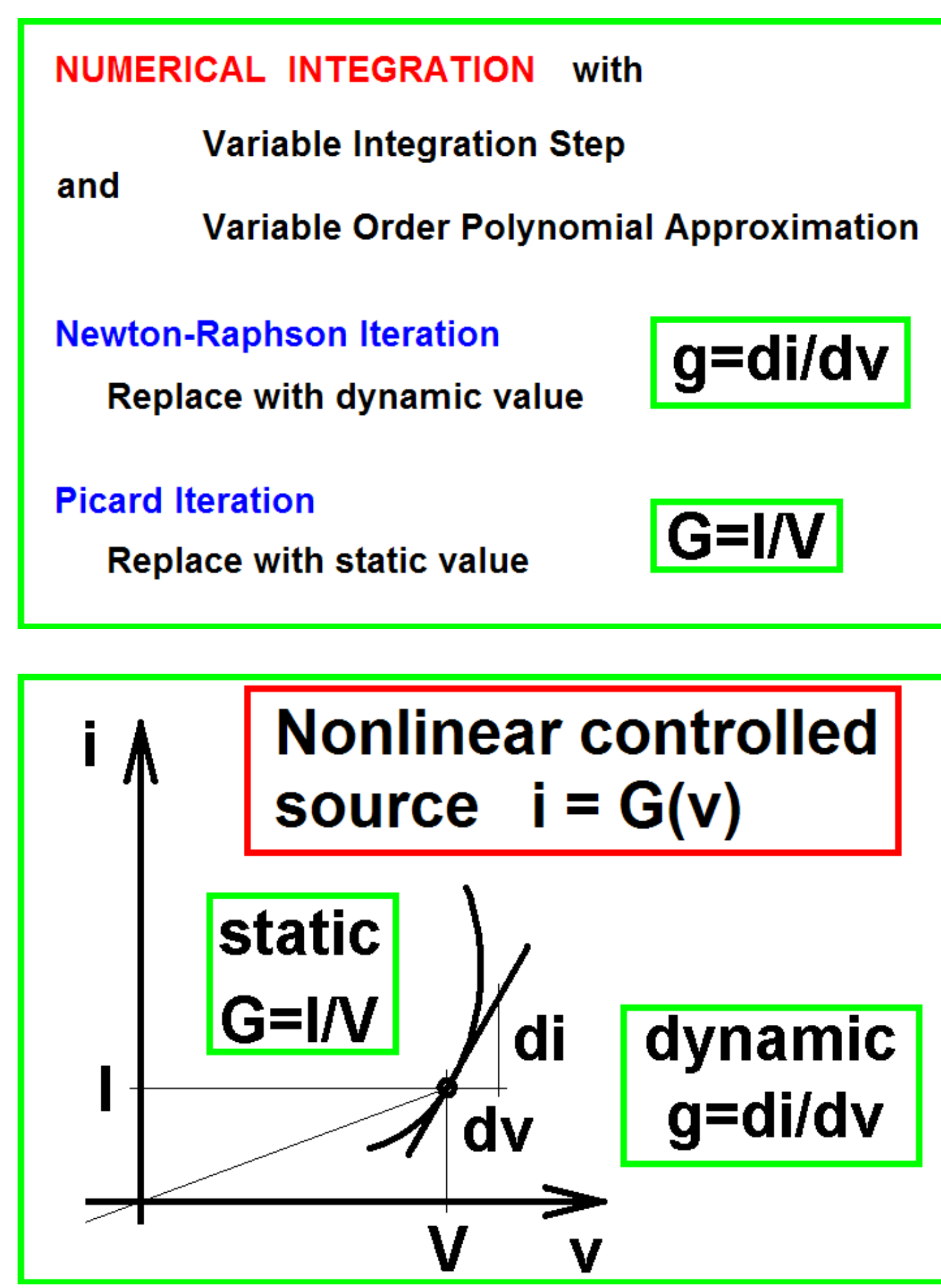
Operational Amplifiers
are maded from transistors, resistors and capacitios
-i.e. they are high order nonlinear circuits Models are based on either
lumped element modeling (e.g. BJT transistors, resistors and capacitors) or
macromodeling (1) It make sense to study the eigenvalues of the linear
small signal models used in each integration step
of the numerical simulation process

\section{- It is assumed that a nonlinear circuit can be
treated as a time-vaningn linear circuit.} - Two approaches "frezez" time and replace
nonininarity with dynamic ratio (JACB B IAN) or
with satit ratio (LTV) - It is assumed that the amplifiers are perfect - -i.e. the input inpedance is infinitite and the output

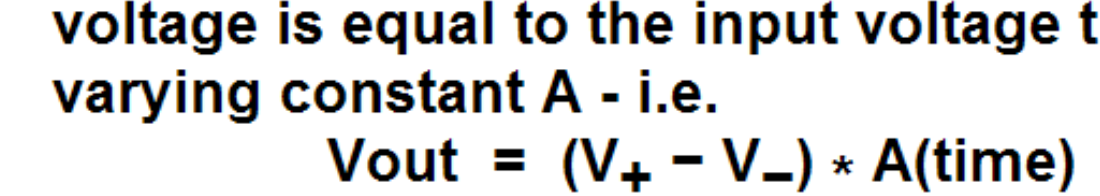

\section{"FREEZE" TIME}

and

with

dynamic ratio (JACOBIAN) or with static ratio (LTV)
HARMONIC OSCILLATOR MODELS Passive lossless LC circuit

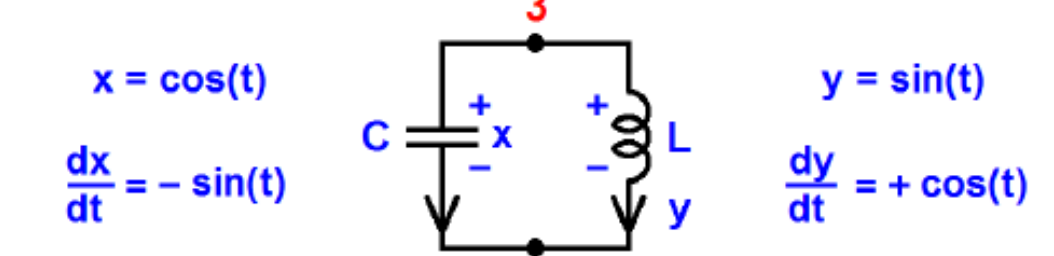
Active ideal integrator circuit

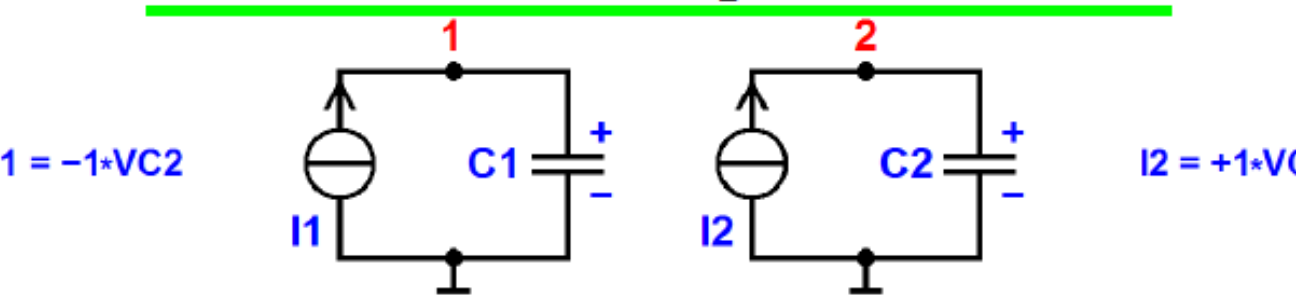

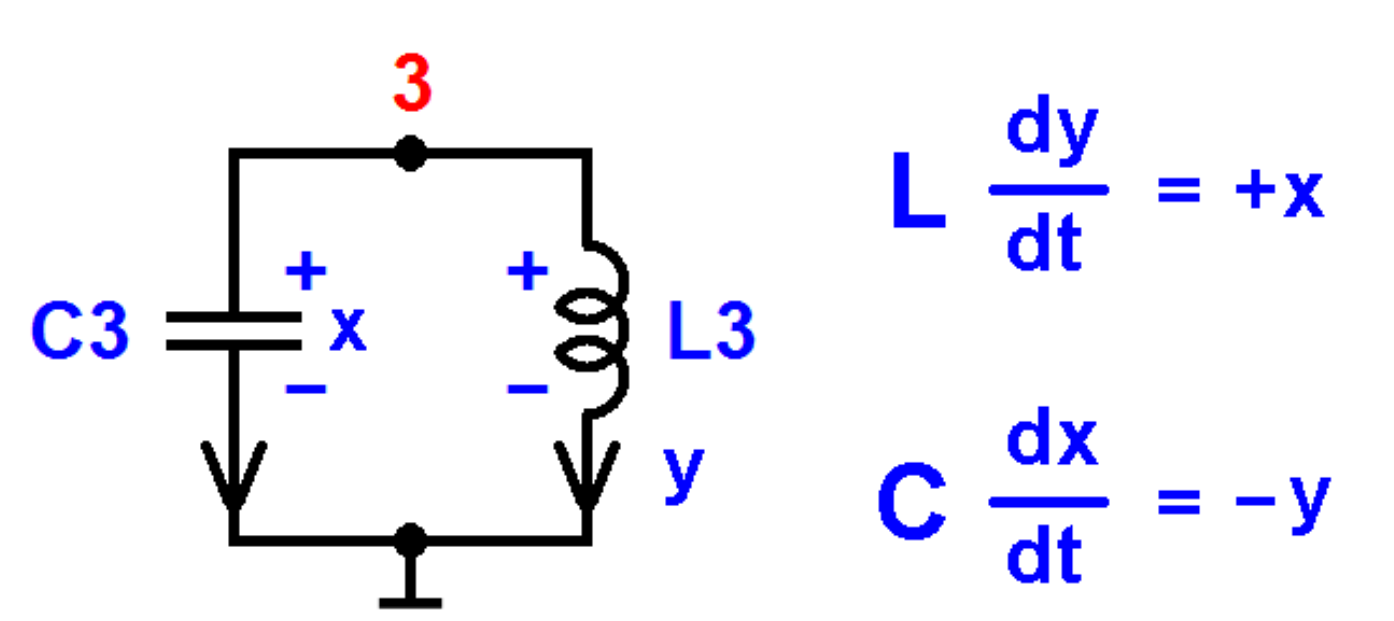
$\frac{d^{2} x}{d t^{2}}+\frac{x}{C L}=0 \quad s= \pm j \frac{1}{\sqrt{C L}}$

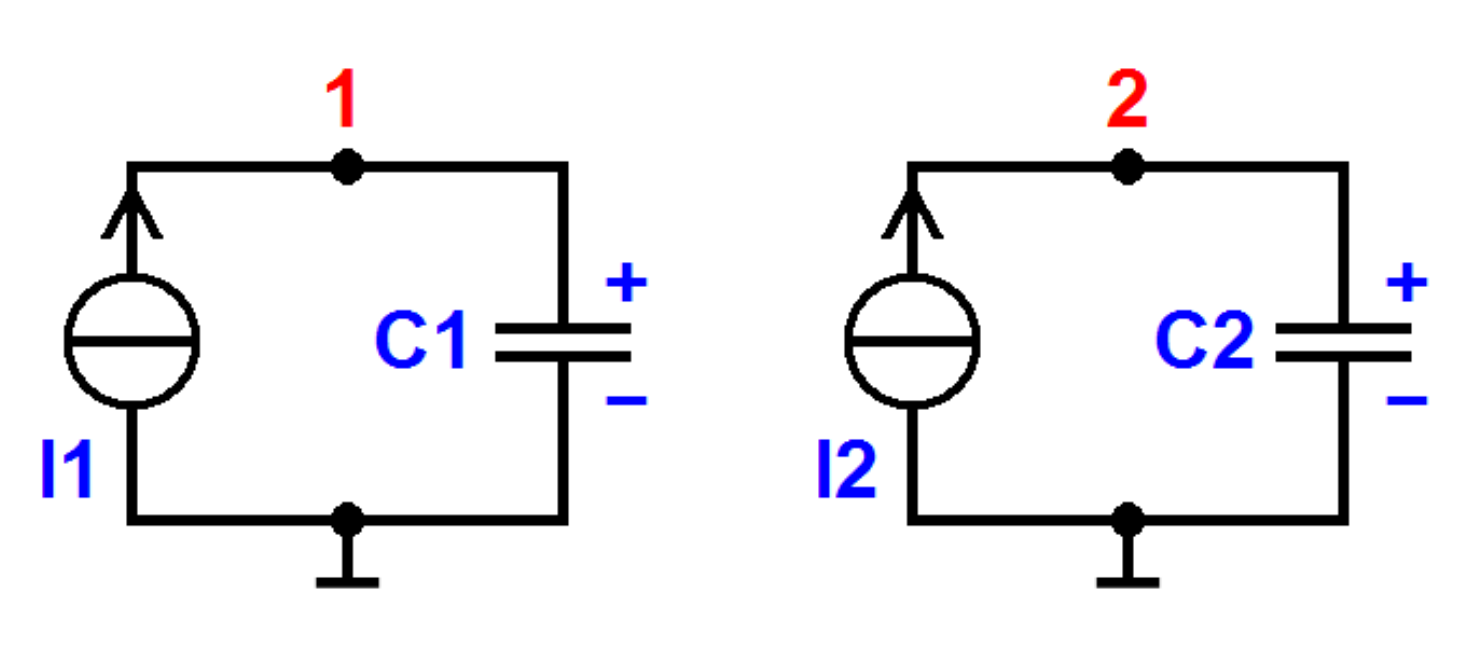
$11=-1+V C 2$ $12=+1 \times V C 1$

$$
s= \pm j \frac{1}{\sqrt{C 1 \times C 2}}
$$

- PSpice comparison of two $100 \mathrm{k} H z$ oscillators
with he following commonent values:

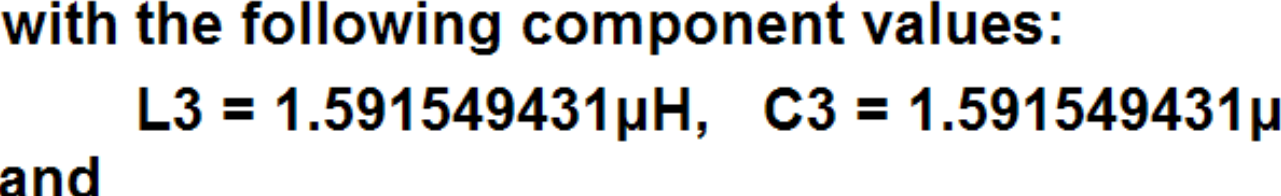
and $C_{1}=C_{2}=1.591549431 \mu \mathrm{F}$ - With an accuracy of $R E L T O L=1 \mu=1 e-6$
in PSpica a very lose agreement between the
models is observed

- The initial conditition is a voltage across the
capacitor and a current equal to zero through the - The voltage becomes a cosine of time and the
current becomes a sine of time
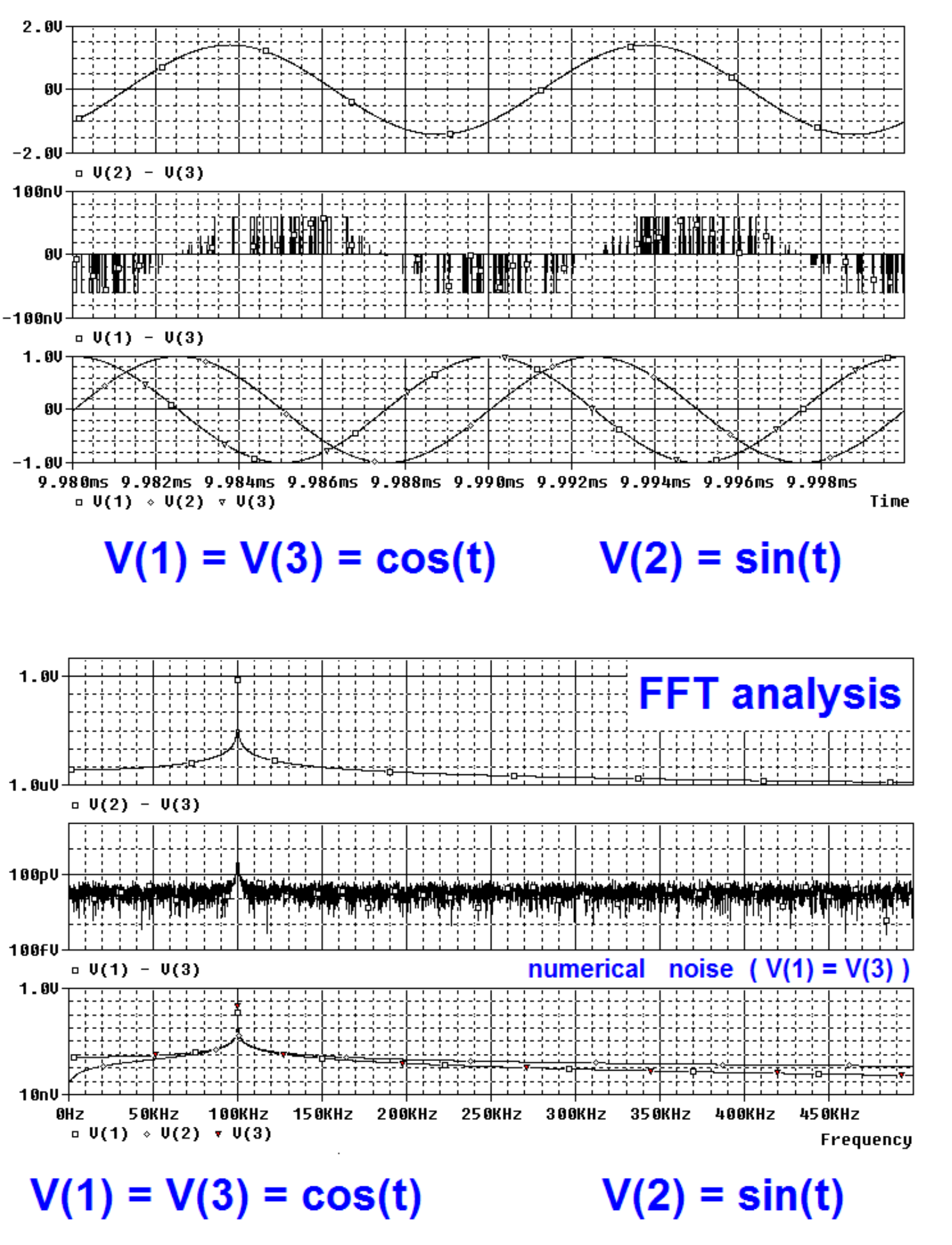

Double Integrator Oscillator
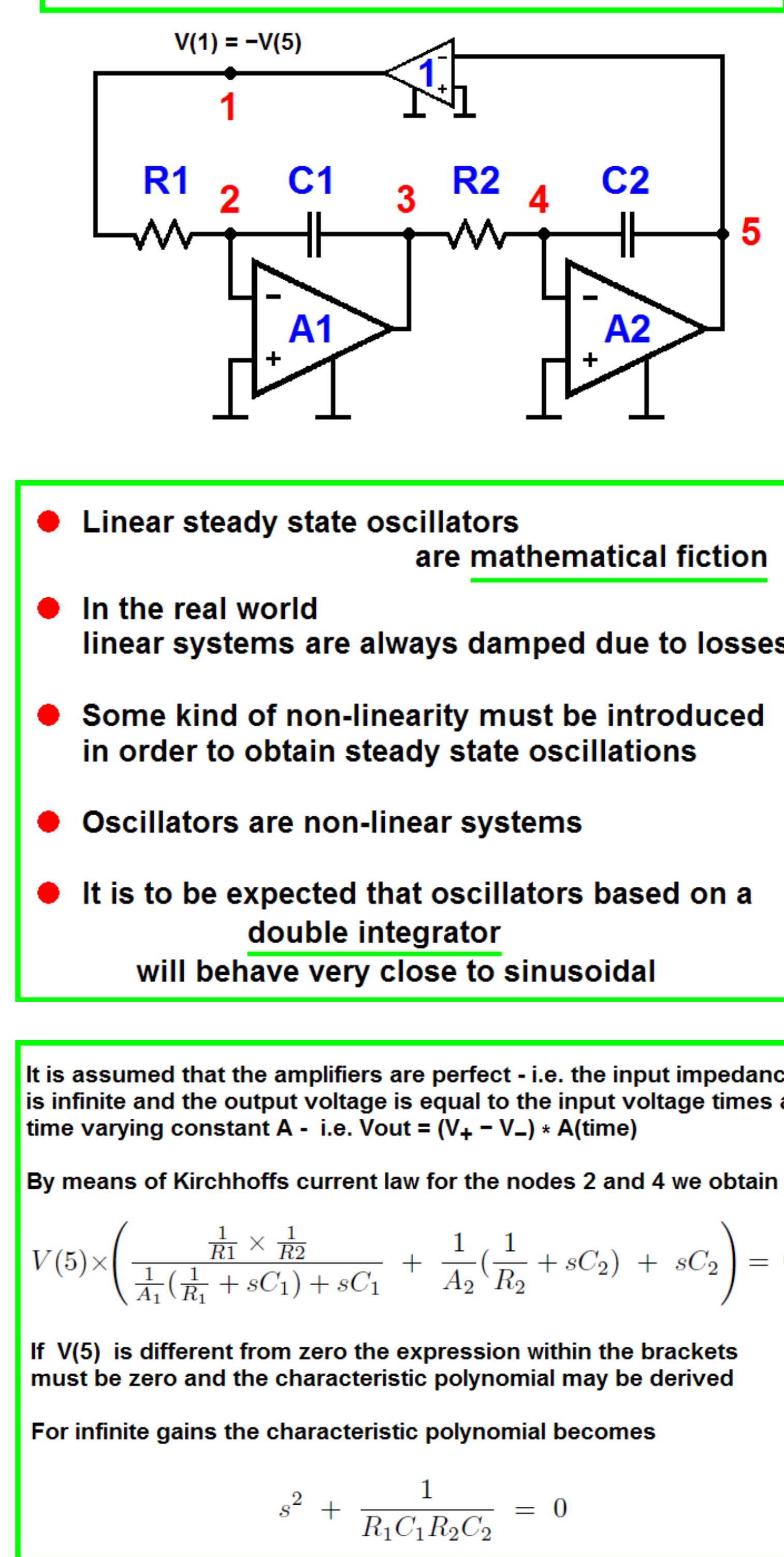

The characteristic polynomit of the circuit becontes The characteristic polynomial of the cires
\[ s^{2}+2 \alpha s+\omega^{2}=0 \]

where $2 \alpha=\frac{C_{1} R_{1}\left(1+A_{1}\right)+C_{2} R_{2}\left(1+A_{2}\right)}{C_{1} R_{1} C_{2} R_{2}\left(1+A_{1}\right)\left(1+A_{1}\right)}$

and $\quad \omega^{2}=\frac{1+A_{1} A_{2}}{C_{1} R_{1} C_{2} R_{2}\left(1+A_{1}\right)\left(1+A_{2}\right)}$

The roots are $\quad p_{1,2}=-\alpha \pm j \sqrt{\left(\omega^{2}-\alpha^{2}\right)}$

OPAMP MACROMODEL

? 0

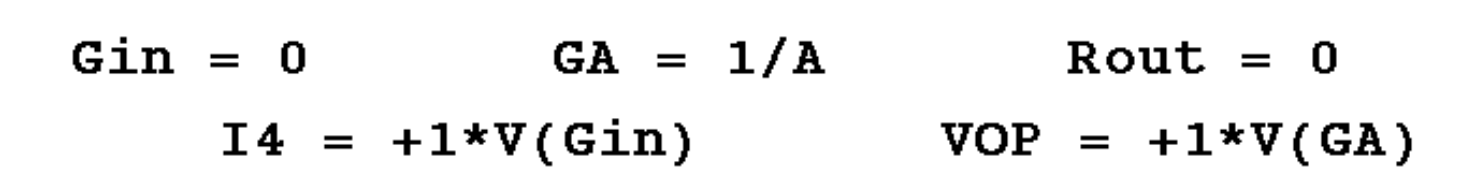
ideal opamp: $\quad A=$ infinite for $G A=0$

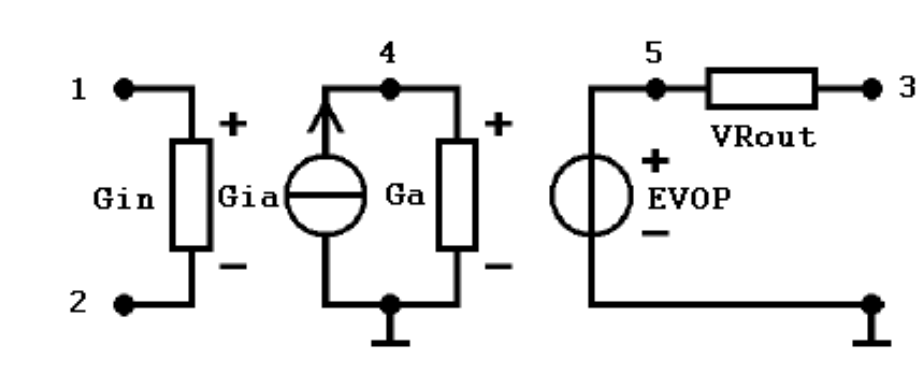

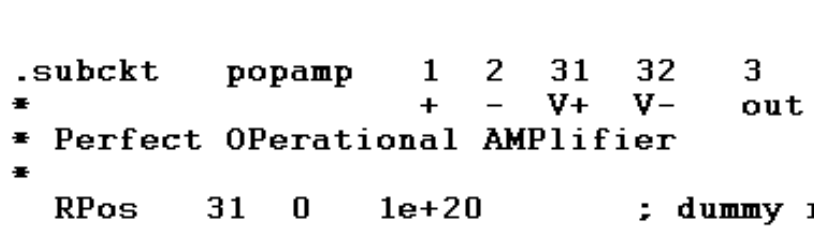

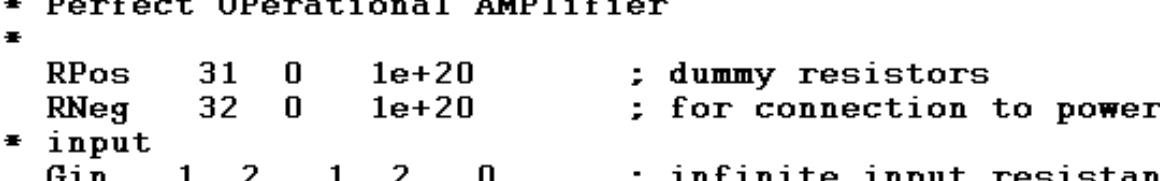

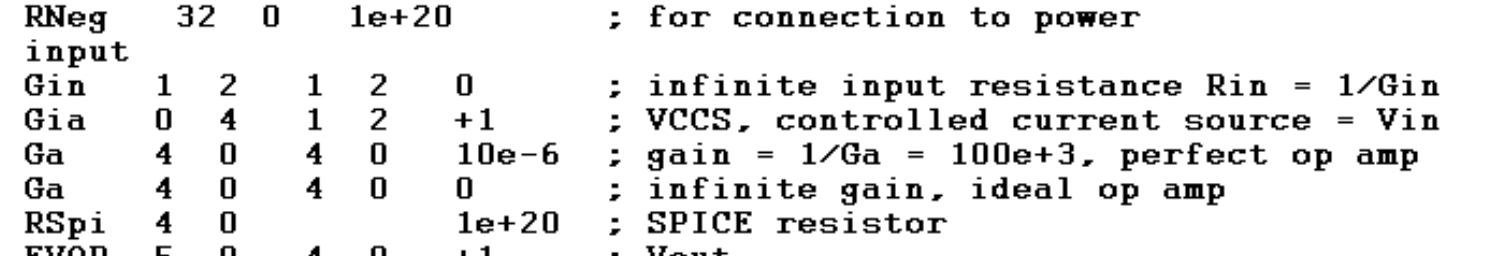

TWO EXPERIMENTS

A same time constants of the integrators

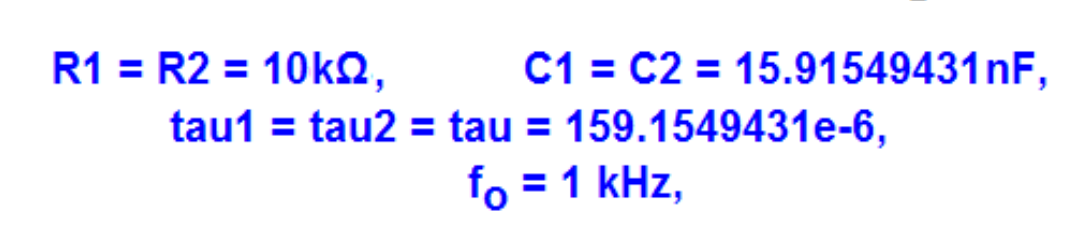

TWO EXPERIMENTS

B Different time constants of the integrators

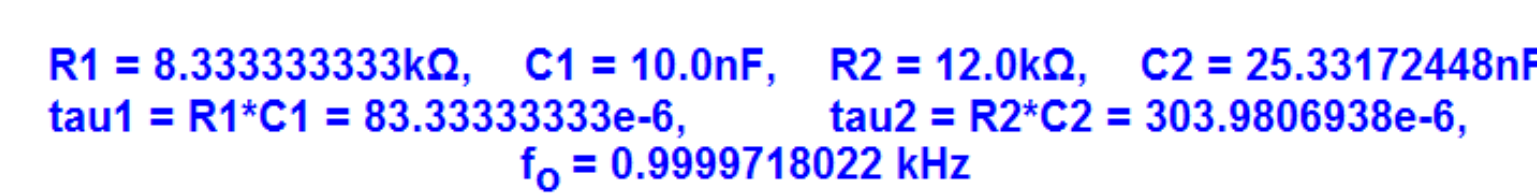

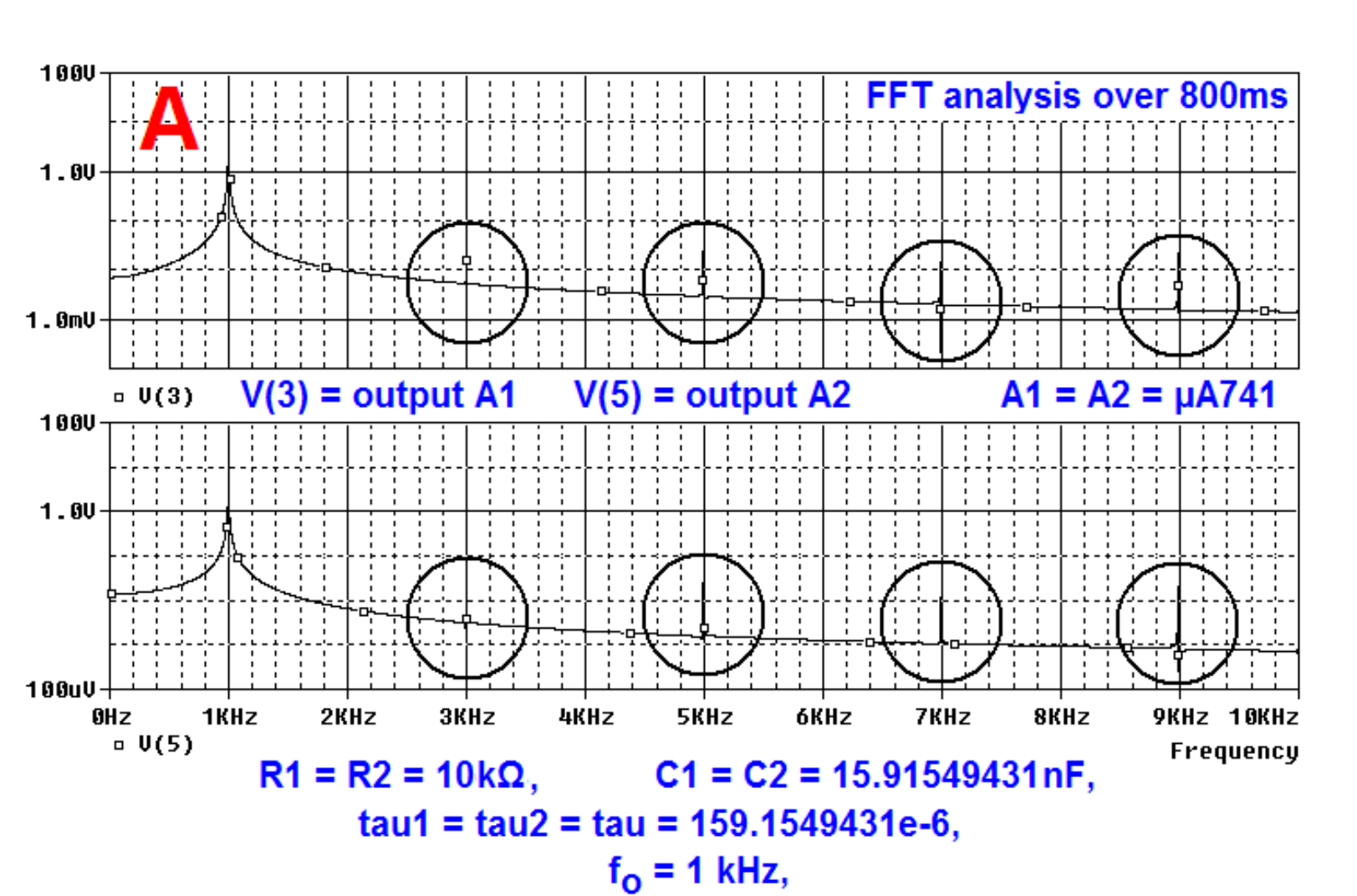

(1)
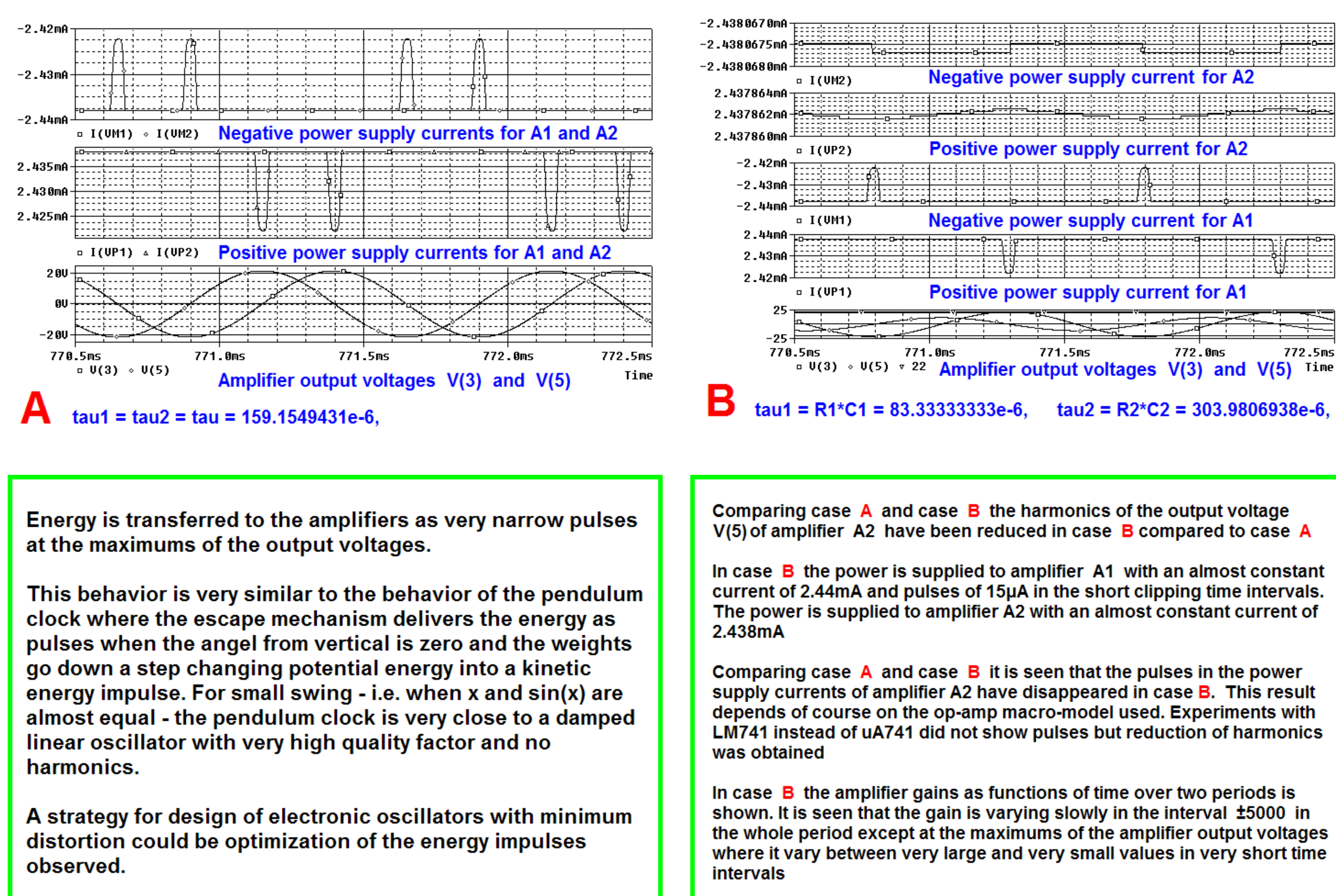

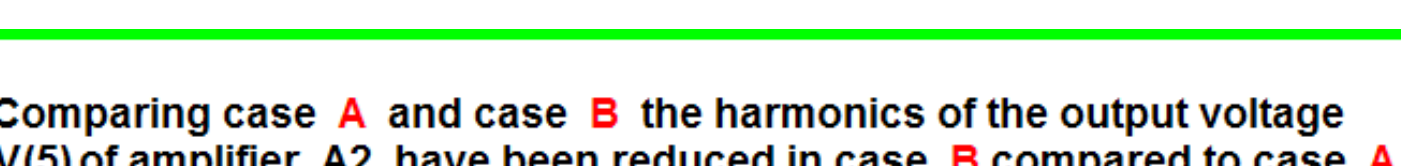

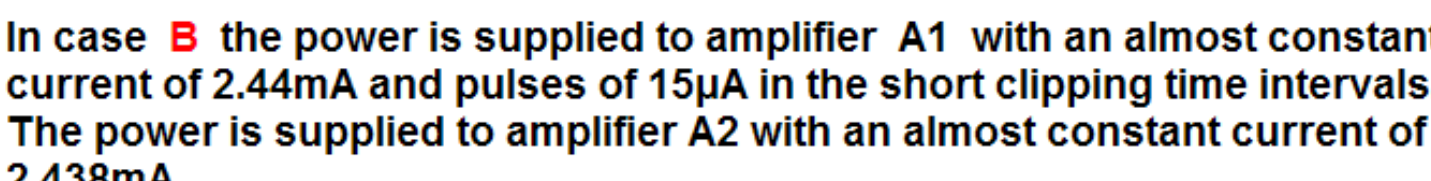

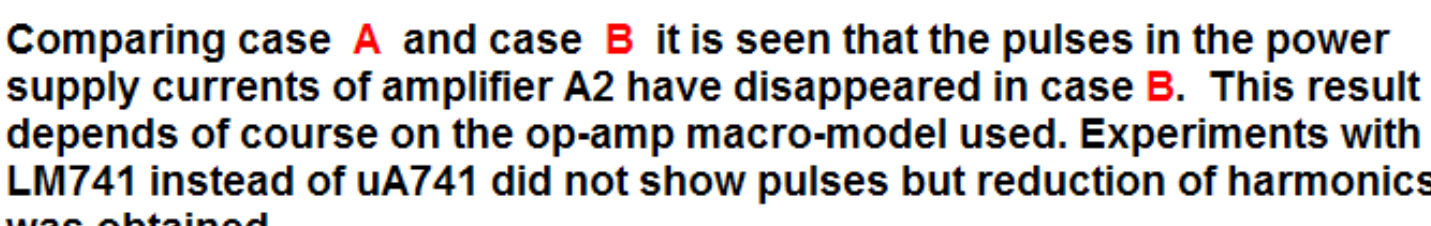

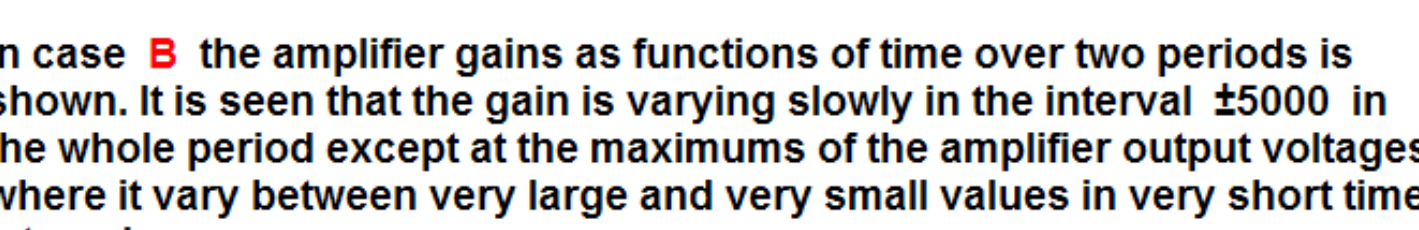

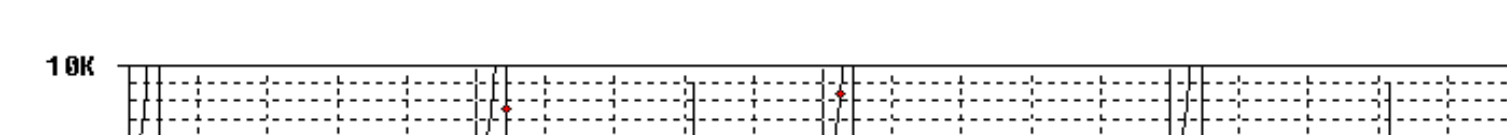

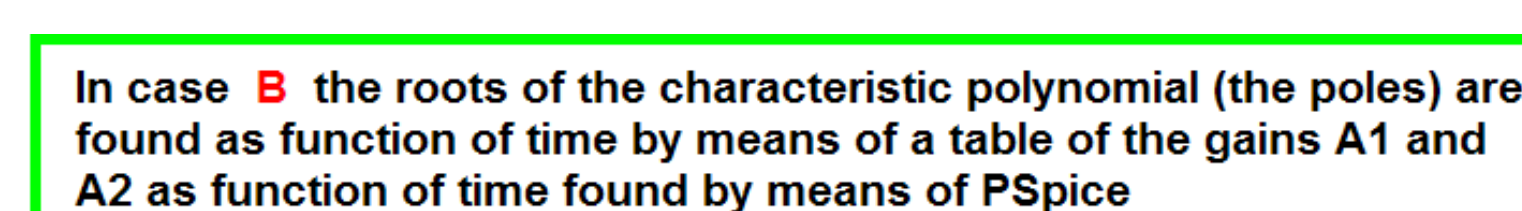

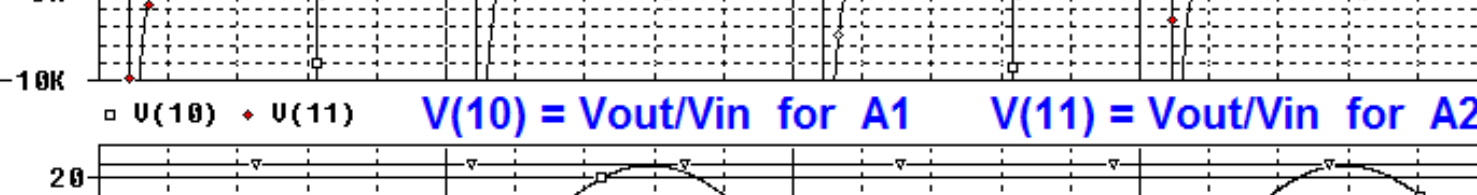
- $\rightarrow 2,+25$

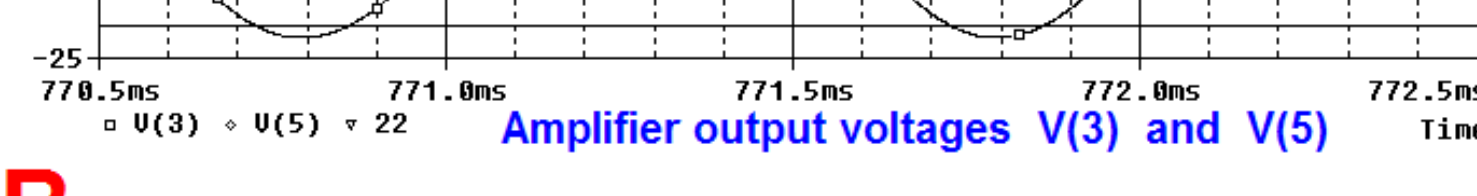

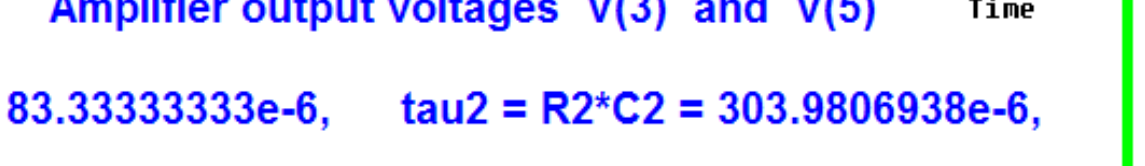

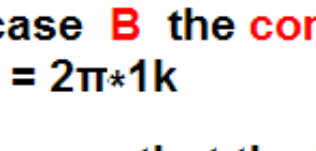

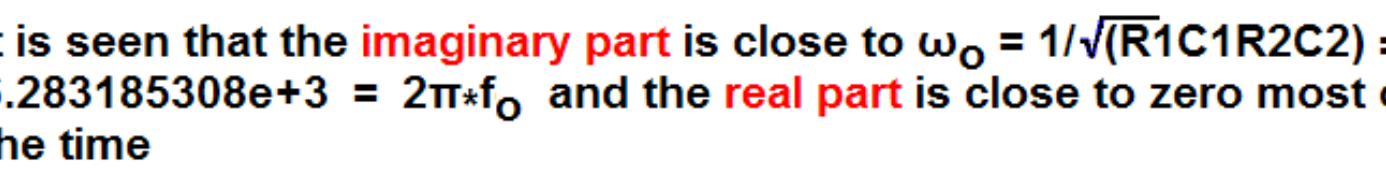

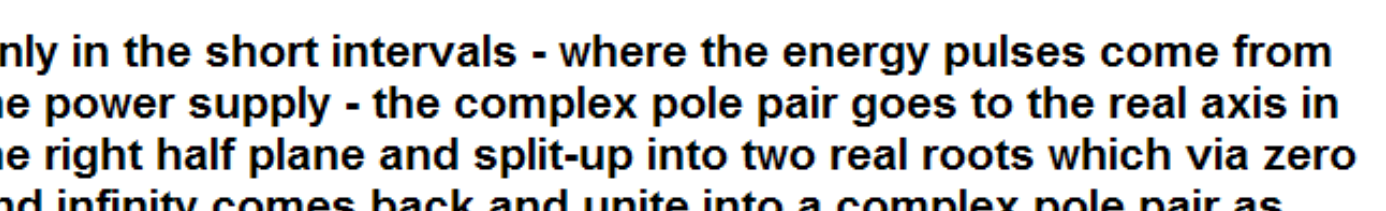

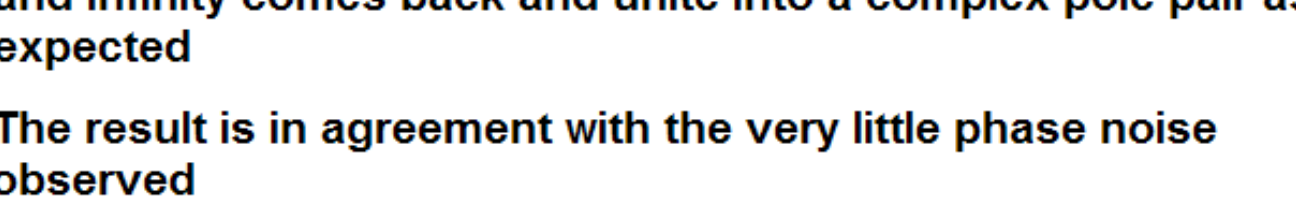

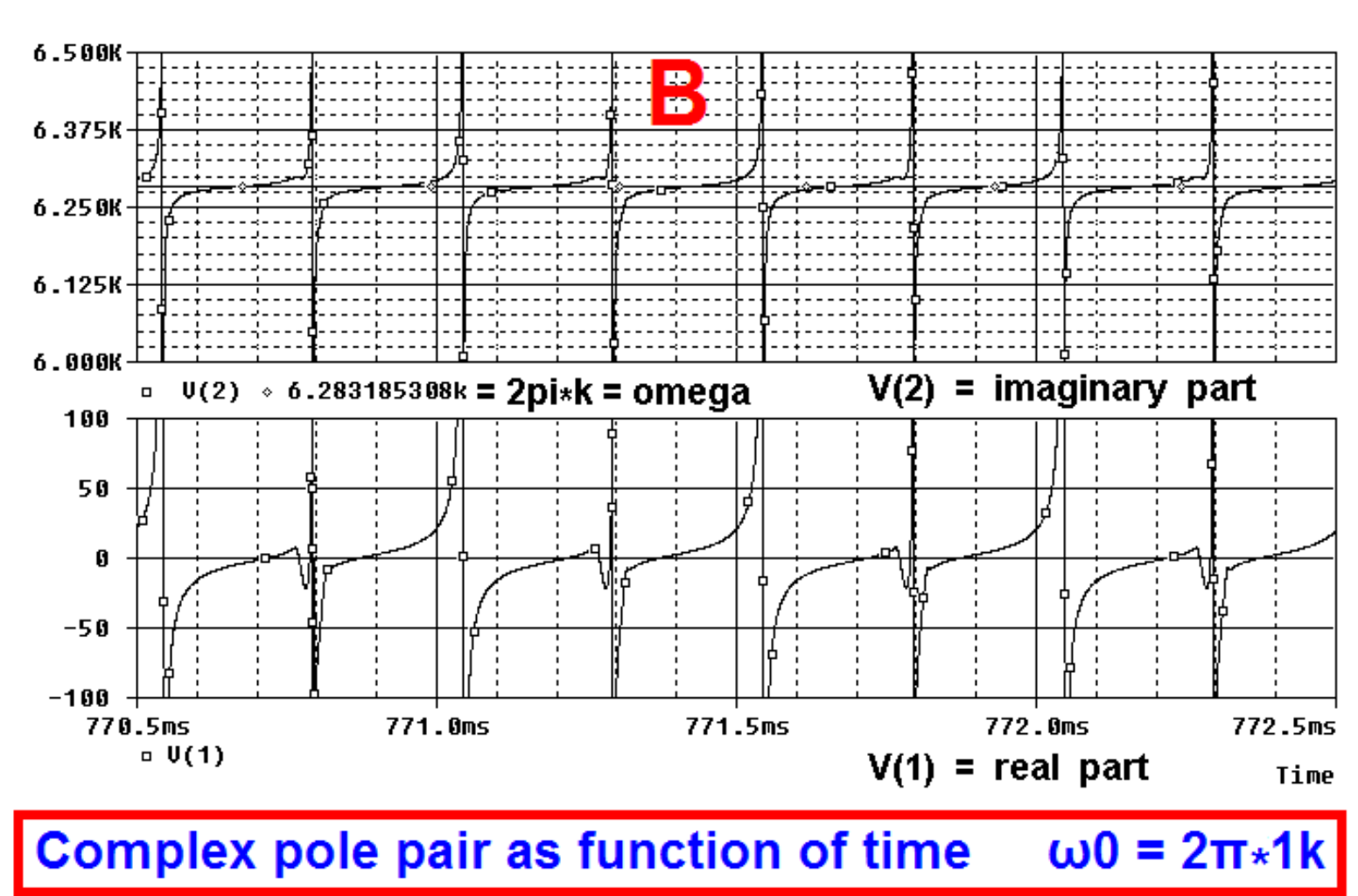

CONCLUSION

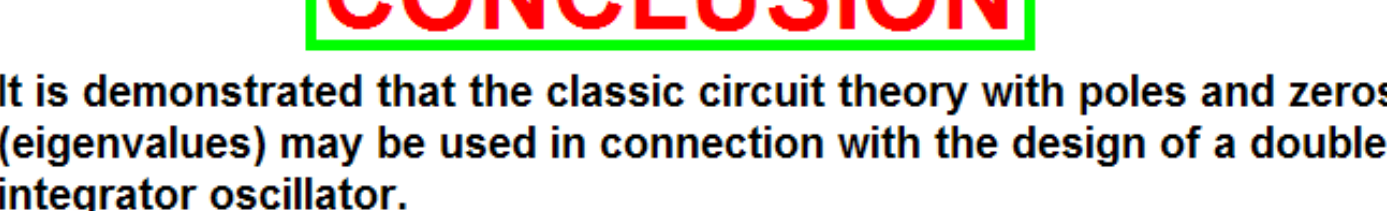

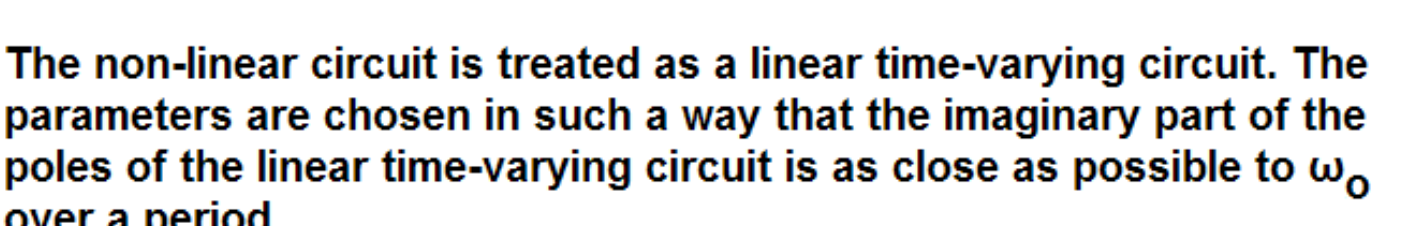

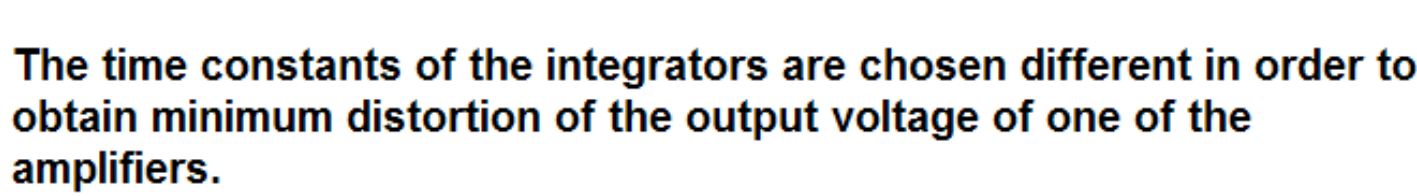

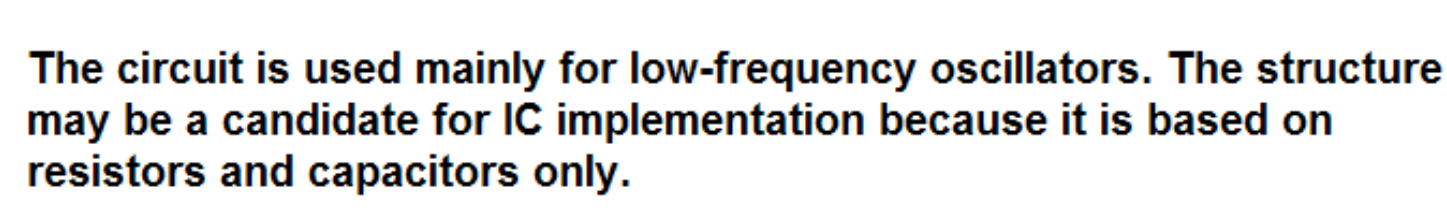

